\title{
Participação Sociopolítica dos Profissionais de Enfermagem de um Hospital Filantrópico de Vitória/Es
}

Sociopolitical Participation of the Nursing Professionals of a Philanthropic Hospital of Vitória / Es

Participación Sociopolítica de los Profesionales de Enfermería de un Hospital Filantrópico de Vitoria / Es

Maryellen Polezi Pereira ${ }^{1}$, Caroline Feitosa Dibai de Castro², Bruno Henrique Fiorin ${ }^{3}$

\section{Resumo}

Objetivou-se descrever os aspectos relacionados à participação sociopolítica da equipe de enfermeiros e técnicos de enfermagem. Trata-se de pesquisa descritiva, com delineamento transversal, realizada no Hospital Santa Casa de Misericórdia de Vitória/ES. Incluíram-se os enfermeiros e técnicos de enfermagem e excluíram-se enfermeiros e técnicos de enfermagem que estavam de licença médica no período de coleta de dados. A análise dos dados foi feita por meio do programa estatístico SPSS 17. Participaram do estudo 282 profissionais de enfermagem, com prevalência do sexo feminino (82,3\%). Os cargos de nível médio responderam por $75,5 \%$ dos participantes, sendo seguidos pela categoria de enfermeiros assistenciais, com $24,5 \%$. Em relação a lutas

\footnotetext{
${ }^{1}$ Bacharel em Enfermagem - EMESCAM, Especialização em Oncologia - EMESCAM. E-mail: mayreppe@ hotmail.com

${ }^{2}$ Bacharel em Enfermagem, Mestre em Administração - FUCAP; Doutorado em Saúde Coletiva - UFES, Professora Assistente EMESCAM. E-mail: Caroline.castro@emescam.br
}

de classe, percebe-se maior interesse dos enfermeiros, com prevalência da classe masculina, mesmo sendo eles a minoria na equipe. Ainda existem profissionais que não conhecem nem participam de nenhuma entidade de representação, mesmo sabendo que a associação ao Conselho Regional de Enfermagem (COREN) é obrigatória para o exercício da enfermagem. A organização política da enfermagem brasileira é caracterizada por avanços e retrocessos. Embora exista um número expressivo de profissionais interessados na política, é necessário maior envolvimento da categoria.

Palavras-chaves: Perfil da enfermagem; Equipe de enfermagem; Política.

\section{Abstract \\ The objective of this paper is to describe the aspects related to the sociopolitical

\footnotetext{
${ }^{3}$ Especialista em Gestão dos Serviços de Enfermagem - UNIFESP, Mestre em Saúde Coletiva - UFES, Doutorado em Cardiologia UNIFESP. Professor Adjunto - UFES. E-mail: brunhenf@hotmail.com
} 
Revista Eletrônica Gestão \& Saúde ISSN: 1982-4785 Pereira MP, Castro CFD, Fiorin BH

participation of the nursing team and nursing technicians. It reports a descriptive research of cross-sectional nature carried out in Santa Casa de Misericórdia, Hospital of Vitória, located in the State of Espírito Santo, Brazil. Nurses and nursing technicians where included in the research while excluding nurses and nursing technicians under medical leave during the data collection period. Data analysis was performed by means of the statistical program SPSS 17. A number of 282 nursing professionals participated in the study, $82.3 \%$ of them being females ( $82.3 \%)$. Medium-level positions corresponded to $75.5 \%$ of the participants, followed by nursing assistants (24.5\%). Respecting to class struggles, a greater interest of the nurses can be noticed, mainly the masculine ones, despite them being the minority of the respondents. There still are professionals who do not know or participate in any representation entity, even though the association to the Regional Nursing Council (COREN) is mandatory for the nursing practice. The Brazilian nursing political organization is characterized by advances and setbacks. Although there is an expressive number of professionals interested in politics, a greater involvement of the category is required.

Key words: Nursing profile; Nursing team; Policy.
Participação Sociopolítica dos Profissionais

\section{Resumen}

Describir los aspectos relacionados a la participación sociopolítica del equipo de enfermeros y técnicos de enfermería. Se trata de una investigación descriptiva, con delineamiento transversal; el escenario fue el Hospital Santa Casa de Misericordia de Vitória / ES. Se incluyeron los enfermeros y técnicos de enfermería y excluídos enfermeros y técnicos de enfermería que estaban de licencia médica en el período de recolección de datos. El análisis de los datos fue realizado a través del programa estadístico SPSS 17. Participaron del estudio 282 profesionales de enfermería. Se observó una prevalencia del sexo femenino $(82,3 \%)$, se destacan los cargos de nivel medio $(75,5 \%)$, seguido por la categoría de enfermeros asistenciales (24,5\%). En relación a luchas de clase, se percibe un mayor interés de los enfermeros, con participaciones de la clase masculina en mayor prevalencia, aun siendo ellos la minoría en el equipo. En el caso de la enfermería, las personas que no conocen y no participan en ninguna entidad de representación, aun sabiendo que la asociación al Consejo Regional de Enfermería (COREN) es obligatoria para el ejercicio de la enfermería. La organización política de la enfermería brasileña está impregnada de avances y retrocesos. Aunque existe un número expresivo de interés en la política es necesaria una mayor participación de la categoría. 
Revista Eletrônica Gestão \& Saúde ISSN: 1982-4785

Pereira MP, Castro CFD, Fiorin BH

Descriptores: Perfil de la enfermería; Equipo de enfermería; Política.

\section{Introdução}

A equipe de enfermagem é considerada uma grande força de trabalho nos serviços de saúde, representando mais de $60 \%$ dos profissionais de saúde na área assistencial e administrativa. Este trabalho se desenvolve de forma coletiva e em colaboração com outros profissionais da área da saúde, no sentido de estabelecer constante multidisciplinaridade. Fundamentase em um saber consolidado que deve fornecer bases para a prática do cotidiano, além de subsidiar a proposição de caminhos para o enfrentamento dos problemas de saúde da população, promovendo medidas de promoção, prevenção, cura e reabilitação. ${ }^{1}$

A qualidade de vida dos trabalhadores de enfermagem é uma incógnita, pois estes lidam com a população geralmente no momento mais complexos do ser humano, que é o adoecimento. No Brasil, os trabalhadores de enfermagem representam o maior contingente dentre as categorias trabalhistas inseridas nas instituições de saúde, computando 1.804.535 enfermeiros e técnicos. São também os que mais enfrentam condições precárias de trabalho por estarem expostos a uma variedade de elementos geradores de desgaste e estresse. ${ }^{2}$ Esses trabalhadores são submetidos a elevadas cargas de trabalho, categorizadas como biológicas, químicas, mecânicas, físicas, fisiológicas e psíquicas. A carga mais referida

\section{Participação Sociopolítica dos Profissionais}

pelos trabalhadores de enfermagem é a psíquica, muito relacionada ao seu objeto de trabalho, o ser humano, que sofre, sente dor e morre. Sendo assim, o trabalho em enfermagem está relacionado à convivência cotidiana com tais situações, o que pode resultar em estresse contínuo nesses trabalhadores. $^{3}$

Este estudo tem o objetivo de descrever a percepção dos profisssionais de enfermagem de um Hospital Filantrópico de Vitória-ES acerca dos aspectos relacionados à participação sociopolítica da sua categoria profissional.

\section{Revisão de Literatura}

O trabalho rotinizado, parcelado, intensivo, as longas jornadas de trabalho, os plantões noturnos e nos fins de semana, a multiplicidade de funções, a repetitividade e a monotonia, a intensidade e o ritmo excessivo de trabalho, o elevado esforço físico e as posições incômodas, associados à supervisão controladora e à falta de autonomia, podem gerar estresse, fadiga e tensão no trabalhador da enfermagem. ${ }^{3,4}$

Tais fatores colaboram tanto para a precarização da saúde do trabalhador como para o comprometimento da qualidade da assistência prestada aos pacientes e para a própria qualidade de vida do trabalhador da enfermagem, contribuindo, assim, para o surgimento dos acidentes de trabalho, doenças, 
Revista Eletrônica Gestão \& Saúde ISSN: 1982-4785 Pereira MP, Castro CFD, Fiorin BH

incapacidade, absenteísmo e até mesmo abandono da profissão. ${ }^{2}$

É um desafio para o gestor em enfermagem reter bons profissionais, melhorar as condições de trabalho da equipe de sua instituição, garantir a oferta de atendimento de excelência e melhorar continuamente a qualidade da assistência. Sendo assim, torna-se relevante conhecer a força de trabalho da enfermagem, e o retrato amplo e atual é passo inicial para o planejamento de estratégias que visem a melhorar os indicadores de qualidade das instituições de saúde.

Existem várias entidades que representam os profissionais da enfermagem na busca por excelência, todas elas com a missão de integrar as equipes e alcançar objetivos importantes para a categoria. Embora se reconheça a importância clínica e o papel do enfermeiro, a participação política tem sido estimulada. Diante dessa realidade, as entidades de classe, Conselho Regional de Enfermagem (COREN), Conselho Federal de Enfermagem (COFEN), Associação de Enfermagem (ABEN) e os sindicatos de classe convergem para os avanços de formação política. Nesse cenário de processo de formação, podem-se citar as participações específicas de cada entidade: o COREN, com a função de fiscalizar; os sindicatos, para buscar melhorias salariais e trabalhistas; e a ABEN, com formação científica cultural que prima pela qualificação e formação profissional.
Participação Sociopolítica dos Profissionais

As articulações políticas da classe, as reivindicações por melhores condições de trabalho e pelo piso salarial, bem como a democratização do sistema, são assuntos que devem ultrapassar os turnos de trabalho, as reuniões de grupo, de equipe ou as discussões de sala. Sem a articulação política necessária nos espaços coletivos e nos centros de tomadas de decisão, os assuntos se tornam inertes, gerando a convicção de que pouco se pode mudar. Uma organização política se faz por trabalho fortalecido, cuja finalidade é transformar a realidade no âmbito coletivo e individual das condições humanas e de trabalho.

A Fundação Oswaldo Cruz (Fiocruz), por iniciativa do COFEN e objetivando conhecer a força de trabalho do profissional de enfermagem, realizou a Pesquisa Perfil da Enfermagem no Brasil.

\section{Métodos}

Trata-se de pesquisa descritiva, com delineamento transversal, de abordagem quantitativa, realizada no Hospital da Santa Casa de Misericórdia de Vitória-ES, hospital filantrópico de grande porte, sendo referência nas áreas de Infectologia, Ginecologia e Cirurgia Geral. Atende a uma população classe média baixa, da qual $70 \%$ advém do interior do estado do Espírito Santo e do sul da Bahia. De acordo com informações do Núcleo de Internação e Regulação, o hospital conta 
Revista Eletrônica Gestão \& Saúde ISSN: 1982-4785

Pereira MP, Castro CFD, Fiorin BH

atualmente com 234 leitos instalados, dez Unidades de Terapia Intensiva e hemodinâmica não habilitada. As especialidades oferecidas são divididas em 34 leitos de cirurgia geral, treze leitos de oncologia clínica, oito leitos de oncologia cirúrgica, 45 leitos de infectologia e 17 leitos de obstetrícia e ginecologia. As especialidades de gastrologia, pneumologia, cardiologia, hematologia e geriatria são classificadas como clínica médica I, com 18 leitos e Unidades de Terapias Intensivas, que se subdividem em onze leitos de Unidade de Tratamento Intensivo Neonatal (UTIN), e nove leitos de Unidade de Tratamento Intensivo (UTI).

Incluíram-se na amostra os enfermeiros e técnicos de enfermagem, pois, na instituição pesquisada, não há mais auxiliares de enfermagem. Excluídos da amostra os enfermeiros e técnicos de enfermagem que estavam de licença médica no período de coleta de dados, bem como aqueles que se recusaram a participar.

A coleta de dados foi realizada no período de fevereiro a junho de 2016, em horários
Participação Sociopolítica dos Profissionais

alternados dos turnos matutino, vespertino e noturno, por meio de formulário sobre a força de trabalho da enfermagem hospitalar baseado no estudo de Machado e Vieira ${ }^{5}$.

Este estudo atende aos princípios éticos, tendo parecer favorável $\mathrm{n}^{\circ} 1.356 .936$ do comitê de ética e pesquisa-CEP da Escola de Medicina da Santa Casa, sob o CAAE número 51311115.5.0000.5065. Todos os participantes foram informados sobre a pesquisa e só participaram após assinatura do termo de consentimento Livre e esclarecido.

\section{Resultados}

Participaram do estudo 282 profissionais de enfermagem, divididos entre técnicos e enfermeiros, conforme apresentado na Tabela 1. Houve prevalência do sexo feminino $(82,3 \%)$. Quanto à categoria profissional, destaca-se o cargo de técnico de enfermagem $(75,5)$, seguido dos enfermeiros $(24,5 \%)$, com prevalência de suas atividades assistenciais $(16,7 \%)$. A idade média dos participantes é de 38, anos, variando de 23 a 66 anos. 
Tabela 1 -Perfil dos participantes. Vitória, ES, Brasil, 2016

\begin{tabular}{cccc}
\hline \multirow{2}{*}{ SEXO } & Variáveis & $\mathbf{N}^{\mathbf{o}}$ & $\mathbf{\%}$ \\
& Masculino & 44 & 15,6 \\
& Feminino & 232 & 82,3 \\
\multirow{3}{*}{ OCUPAÇÃO } & Omissos & 6 & 2,1 \\
& & & \\
& Enfermeiro & 69 & 24,5 \\
\multirow{3}{*}{ FUNÇÃO } & Téc. Enfermagem & 213 & 75,5 \\
& Enfermeiro assistencial & 47 & 16,7 \\
& Técnico de enfermagem & 213 & 75,5 \\
& Enfermeiro & 19 & 6,7 \\
& administrativo & 3 & 1,1 \\
\hline & Omissos & 282 & $100 \%$ \\
\hline & Total & &
\end{tabular}

Na Tabela 2, observa-se a distribuição em relação ao conhecimento e à participação em questões sociais e políticas da enfermagem. Embora a maioria dos participantes possua interesse, 19,85 relataram não se interessar.
Em relação a lutas da enfermagem, a maioria acompanha as questões relativas ao piso salarial e à jornada de 30 horas de trabalho, enquanto $17,2 \%$ não possui envolvimento com as lutas da profissão.

Tabela 2 - Questões sociais e políticas relacionadas à profissão. Vitória, ES, Brasil, 2016

\begin{tabular}{lcc}
\hline Variáveis & $\begin{array}{c}\text { Frequência } \\
\text { Porcentage } \\
\text { m }\end{array}$ \\
\hline Interesse social e político & & \\
Possui interesse & 143 & 50,70 \\
Não possui & 56 & 19,85 \\
Às vezes & 73 & 25,88 \\
Omisso & 09 & 3,19 \\
\hline Acompanha os movimentos políticos & & \\
Sim & 83 & 29,43 \\
Não & 89 & 31,56 \\
Âs vezes & 102 & 36,17 \\
Não responderam & 08 & 2,83 \\
\hline Projetos políticos que tenha acompanhado nos últimos cinco anos & \\
Jornada de 30 horas & 189 & 67,02 \\
Democratização do sistema COFEN/COREN & 00 & 00 \\
Programa de atualização para Enfermagem (PROENF e & 20 & 7,09 \\
PROTENF) & & \\
Piso salarial & 153 & 54,25 \\
Nenhum & 48 & 17,02 \\
Outros & 00 & 00 \\
\hline
\end{tabular}

Fonte: Questionário aplicado. 
Revista Eletrônica Gestão \& Saúde ISSN: 1982-4785

Pereira MP, Castro CFD, Fiorin BH

Em relação à forma de acompanhamento das questões políticas, nota-se que a maioria dos trabalhadores fica sabendo sobre as mudanças de remuneração e lutas salariais por meio dos
Participação Sociopolítica dos Profissionais

jornais específicos da categoria (34,39\%), seguida dos demais noticiários e do acompanhamento por meio do sindicato, conforme a Tabela 3.

Tabela 3 - De que forma você acompanha as campanhas salariais da categoria.

\begin{tabular}{lcc}
\hline \multicolumn{1}{c}{ Variáveis } & Frequência & Porcentagem \\
\hline Sindicato & 43 & 15,24 \\
Nas assembleias da categoria & 01 & 0,35 \\
Por jornais das entidades & 97 & 34,39 \\
Na mesa de negociação & 04 & 1,41 \\
Demais noticiários que leio & 75 & 26,59 \\
Outras & 01 & 0,35 \\
\hline
\end{tabular}

Fonte: Questionário aplicado

Gráfico 1 - Entidades de enfermagem que você conhece, a que é filiado e de que participa regularmente. Vitória, ES, 2016.

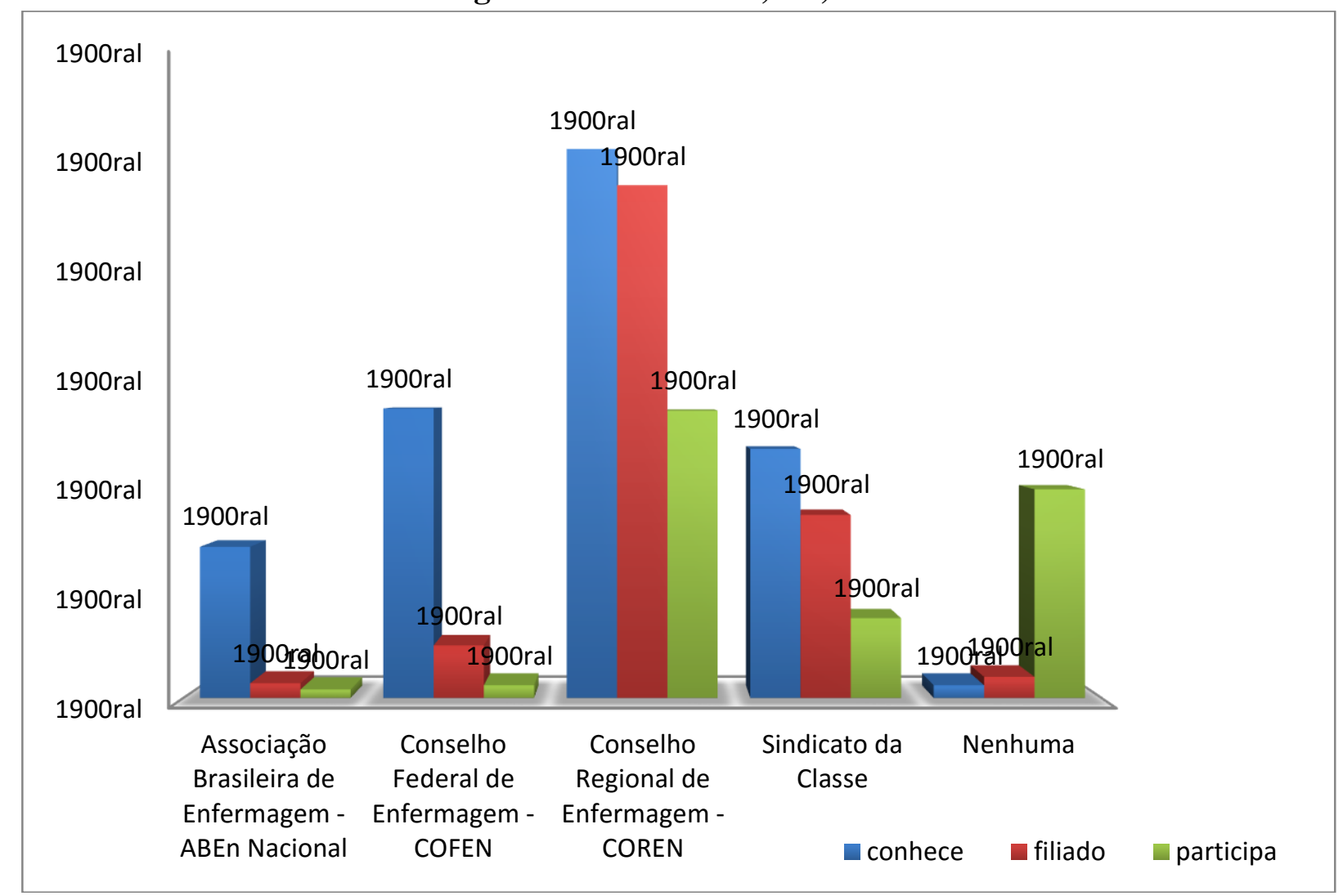

Fonte: Resultado do questionário aplicado 
No Gráfico 1, observa-se que as três entidades de enfermagem mais conhecidas pelo profissional, a qual é filiado e de que participa regularmente foram o COREN, o COFEN e os sindicatos da categoria. O quantitativo de entrevistados que conhecem a Associação Brasileira de Enfermagem é significativamente menor do que os que dela participam, o que chama à atenção e faz com que se reflita sobre a oportunidade de expor os trabalhos realizados pelas associações em nível nacional. Ainda existem profissionais que não conhecem nem participam de nenhuma entidade de representação, mesmo sabendo que a associação ao COREN é obrigatória para o exercício da enfermagem.

Em relação aos princípios éticos, a maioria dos profissionais conhece parcialmente o Código de Ética da profissão e apenas 21,6\% o conhece totalmente; $25,9 \%$ relataram já ter cometido tal tipo de erro e $66,7 \%$ nunca agiu fora desses princípios.

No Gráfico 2, observa-se a concepção da sociedade e do paciente em relação à enfermagem, utilizando-se a concepção do profissional. A maioria dos profissionais possui a percepção de que a enfermagem é vista positivamente pela sociedade e pelos pacientes.

\section{Gráfico 2 - A imagem que sociedade e dos pacientes têm da profissão enfermagem. Vitória,} ES, Brasil, 2016.

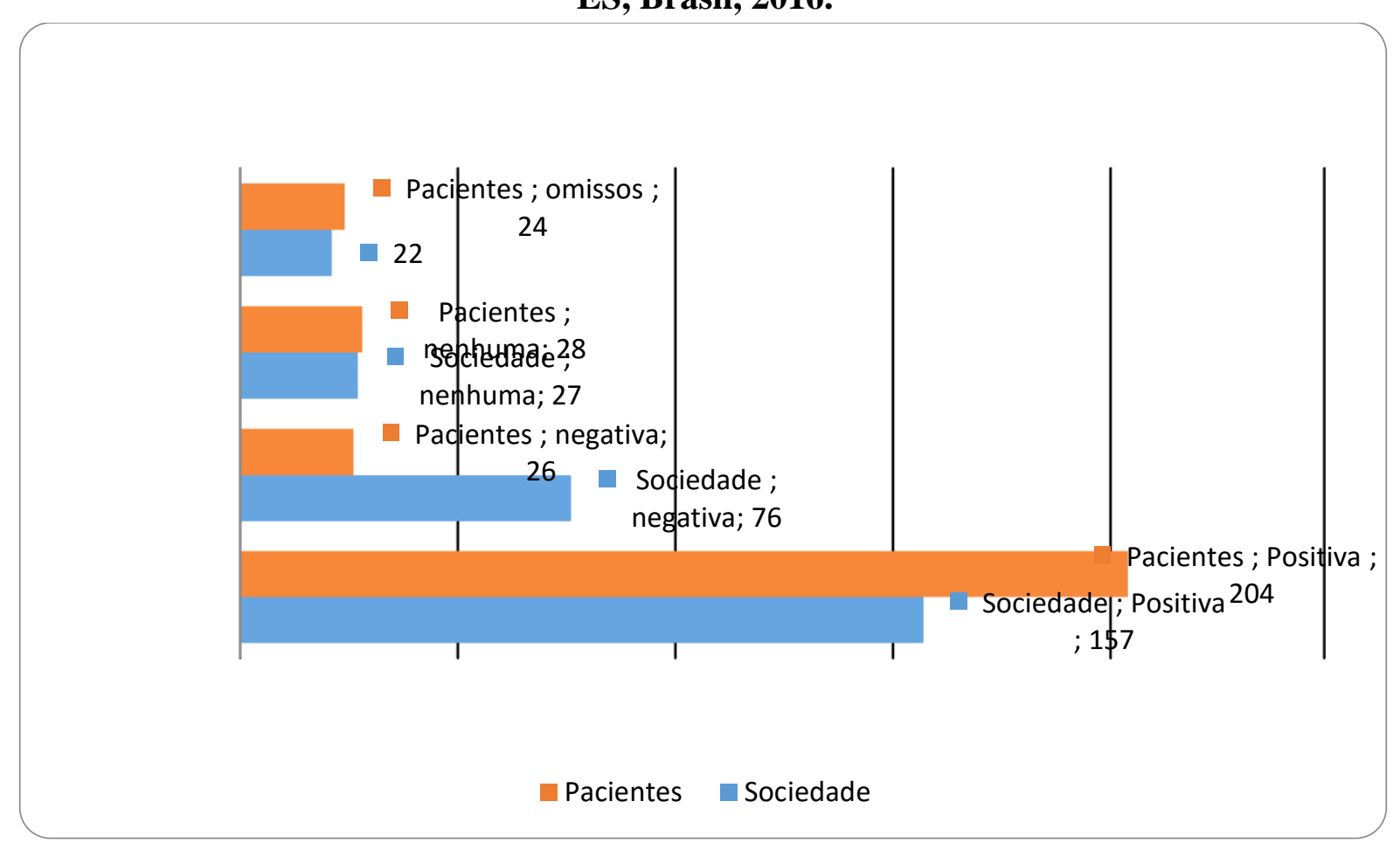

Fonte: Resultado do questionário aplicado.

Comparando-se o técnico de enfermagem com

o enfermeiro em relação à participação política, observa-se, por meio do teste quiquadrado, que, em relação ao Código de Ética, 
Revista Eletrônica Gestão \& Saúde ISSN: 1982-4785 Pereira MP, Castro CFD, Fiorin BH

os profissionais do sexo masculino possuem maior conhecimento do que os do sexo feminino $(\mathrm{p}<0,001)$. Quando se comparam o interesse político e o envolvimento em movimentos, nota-se que os profissionais de nível superior possuem maior interesse por estas questões $\quad(p<0,005$ e $\quad p<0,045$ respectivamente), com destaque para a questão da formação política intrínseca na graduação.

\section{Discussão}

O estudo foi desenvolvido em um hospital filantrópico de Vitória de 234 leitos. A força de trabalho da equipe era composta por 282 profissionais de enfermagem, sendo $75,5 \%$ de técnicos de enfermagem e o restante de enfermeiros assistenciais e administrativos. Esses dados vão ao encontro do perfil apresentado pela Fiocruz.

De acordo com dados do Instituto Brasileiro de Geografia e Estatística $(\mathrm{IBGE})^{6}$, a área da saúde é composta por um grupo de 3,5 milhões de trabalhadores, dos quais, segundo Machado $^{7}, 80 \%$ são técnicos de enfermagem, corroborando, assim, os dados de que $75,5 \%$ de seus profissionais são da área técnica.

A prevalência das mulheres na equipe de enfermagem (82,3\%) é de grande relevância, o que não reduz a importância e a existência da equipe masculina, com 15,6\%. De acordo com Machado ${ }^{7}$, a equipe de enfermagem é historicamente feminina e, ao longo da história, a mulher vem construindo e
Participação Sociopolítica dos Profissionais

conquistando seu espaço no mundo do trabalho, na sociedade e na política. $O$ resultado das lutas e vitórias é visivelmente percebido na atualidade, e os dados da pesquisa em nível nacional realizada pela Fiocruz em $2016^{7}$ confirmam essa assertiva, ou seja, $85,1 \%$ são femininas e $14,4 \%$ masculinos, o que permite notar o processo d e aumento do número de profissionais do sexo masculino na categoria.

Ao longo da história humana, o conhecimento e a participação política vêm se desenvolvendo e se aprimorando, visto se tratar de aspectos que interferem na vida dos cidadãos e de caráter multiprofissional. A política vem questionar o que foi construído e implantar novas ideias para que o exercício seja diversificado e objeto de reflexões constantes. ${ }^{8}$ Segundo Melo $^{9}$, durante a formação acadêmica, a participação na política dos estudantes é pouco estimulada, a exemplo da atuação junto aos diretórios acadêmicos, sob a desculpa de dedicação aos estudos, quando comparados aos quesitos técnicos. As disciplinas sobre formação política e social são restritas nos currículos e se apresentam como as menos valorizadas pelos acadêmicos ao longo da formação.

A importância do interesse por questões políticas e sociais $(50,70 \%)$ se deve ao fato que a enfermagem utiliza diferentes instrumentos para viabilizar seu trabalho, o que corrobora Oliveira $^{[10]}$, que relata o interesse político da 
Revista Eletrônica Gestão \& Saúde ISSN: 1982-4785 Pereira MP, Castro CFD, Fiorin BH

categoria por entender que o enfermeiro é agente de mudanças e mobiliza as pessoas com as quais interage. $\mathrm{O}$ mesmo autor entende que "o homem despolitizado compreende mal o mundo em que vive e é facilmente manobrado por aqueles que detêm o poder". ${ }^{10}$

Em relação à participação política nas entidades de classe, a maioria dos profissionais, às vezes, acompanha $(36,2 \%)$ movimentos políticos; a equipe de enfermagem não revela uma valorização política significativa na gestão, com participações diretas nas entidades de classe. Assim, faz-se necessário que a equipe de enfermagem reconheça a importância no desempenho da sua participação nas funções gestoras, pois, mesmo ocupando esses espaços, faltam preparo para conduzir determinadas situações e reflexão sobre seu poder frente às posições ocupadas. ${ }^{9}$

Segundo Lessa ${ }^{11}$, os enfermeiros e os demais profissionais estão desarticulados do processo político, tanto para desenvolver como para lutar. É imperativo que se abram caminhos nesse modo de ser e fazer da categoria, com a inclusão dos profissionais de saúde, de modo a ampliar o conhecimento para que se reflita cada vez mais nos profissionais e na sociedade.

O conhecimento sociopolítico molda todos os demais padrões do saber, pois comtempla o contexto em que as pessoas interagem, em especial, pacientes e equipe. $\mathrm{O}$ enfermeiro
Participação Sociopolítica dos Profissionais

torna-se um agente de mudanças, de alterações em potencial, devendo utilizá-las visando à coletividade, interferindo politicamente nas questões de saúde determinantes da realidade. [10]

Em relação aos projetos acompanhados nos últimos cinco anos, há maior envolvimento e conhecimento $(67,02 \%)$ do Projeto de Lei ${ }^{\circ}$ 2.295/2000, que regulamenta a jornada dos trabalhadores de enfermagem brasileira em 30 horas semanais e que tramita no Congresso Nacional desde o ano 2000. Pode-se perceber que o fato de tal projeto estar em discussão pública e ser acompanhado pelos profissionais não significa que ele se tornou uma questão pública, visto que, após 16 anos de sua elaboração, ainda existem profissionais que não acompanham suas discussões.

As questões políticas abordadas pelas entidades de classe são acompanhadas pelos profissionais por meio dos jornais das categorias $(34,39 \%)$, divulgados pelos Sindicatos, Conselhos de Enfermagem e pela Associação de Enfermagem. Para a organização de enfermagem, Santos ${ }^{12}$ discorre sobre as lutas em andamento: além das questões salariais, o investimento maciço na mobilização da categoria e o investimento na conquista da autonomia e da realização pessoal pelo trabalho, é necessário mobilizar toda a categoria para que o 'gigante' adormecido possa ser representativo nos cenários de 
Revista Eletrônica Gestão \& Saúde ISSN: 1982-4785 Pereira MP, Castro CFD, Fiorin BH

negociação, aumentando a visibilidade da profissão.

As entidades de classes são órgãos que, motivados pelo interesse coletivo de uma categoria profissional, tentam melhorar as condições que interferem no processo de trabalho. Na enfermagem, têm-se os sindicatos, o COREN e a ABEN. Embora possuam propósitos diversos, são imprescindíveis como órgãos que representam os interesses culturais, políticos e econômicos dos profissionais de enfermagem em nível nacional. Nessa perspectiva, tais entidades devem unir esforços para a valorização e o reconhecimento da categoria.

A entidade política representativa da enfermagem brasileira, de acordo com Lessa ${ }^{11}$, iniciou-se após a diplomação da turma pioneira da Escola Anna Nery, em 1925, onde, a princípio, a ideia seria criar uma associação de ex-alunas. Assim, em 1926, foi fundada a Associação Nacional de Enfermeiras Diplomadas (ANED). Em 1954, com caráter cultural, científico e político, tornou-se a Associação Brasileira de Enfermagem (ABEN), atuando via meios de informação e conhecimento sobre enfermagem, sendo alguns deles a Revista Brasileira de Enfermagem, os Congressos Brasileiros de Enfermagem, a Semana Brasileira de Enfermagem, os Comitês de Ensino de Graduação e Pós-Graduação e o Jornal de Enfermagem. Embora a ABEN seja a mais
Participação Sociopolítica dos Profissionais

antiga, apenas uma minoria dos participantes (7\%) é associada a ela, o que ressalta que, apesar da suma importância e tamanha atuação, não existe reconhecimento total da categoria em relação à sua existência e ao seu papel na formação profissional da categoria.

Por meio da Lei $n^{0} 7.498 / 86^{13}$, só pode exercer a profissão de enfermagem o profissional que tiver inscrição aprovada no Conselho Regional de Enfermagem. Nesse sentido, sendo graduado ou técnico de enfermagem, os profissionais de ambos os níveis de formação ficam condicionados ao cumprimento do Código de Ética profissional da área em questão.

Em relação à ética, Fortes ${ }^{14}$ se refere à reflexão crítica sobre o comportamento humano, a qual interpreta, discute e problematiza, investiga os valores, os princípios e o comportamento moral, à procura do 'bom', da 'boa vida', do 'bem-estar da vida em sociedade'. Os princípios éticos são fundamentais para nortear as ações a serem tomadas diante de vários contextos sociais e profissionais.

Segundo Schneider ${ }^{15}$, a equipe de enfermagem precisa possuir, além de habilidades técnicas e práticas, compromisso ético para administrar ao máximo as ocorrências prejudiciais ao paciente; logo é fundamental gerenciar situações de risco na assistência de enfermagem. Nesse sentido, os profissionais precisam conhecer as responsabilidades ética, profissional e penal de suas ações, e também 
Revista Eletrônica Gestão \& Saúde ISSN: 1982-4785 Pereira MP, Castro CFD, Fiorin BH

os seus direitos e deveres, de forma a evitar negligência, imperícia ou imprudência. Confrontando Schneider ${ }^{15}$, a maioria dos profissionais relata que conhece parcialmente o Código de Ética da profissão $(68,8 \%)$.

Segundo o estudo de Persegona $^{8}$, o padrão ético não envolve apenas o conhecimento do seu código profissional, criado em 1955, mas o estabelecimento de objetivos e intervenções adequados, de forma a que os clientes realizem escolhas e avaliem o que é bom, certo ou errado. O desenvolvimento do conhecimento ético é cada vez mais necessário, visto que, em seu cotidiano, os profissionais se veem confrontados com questões que exigem escolhas. Julgamentos éticos envolvem, muitas vezes, confronto de valores e verdades impostas, normas e interesses, fazendo com que o conhecimento ético na enfermagem requeira tanto o conhecimento empírico como o conhecimento de princípios sobre a sociedade e a profissão em que está inserido.

Em relação à imagem da equipe perante a sociedade e pacientes, revela-se uma positividade na maioria dos entrevistados que contradiz o estudo realizado por Lessa ${ }^{11}$, o qual relata que o saber e o fazer dos enfermeiros ainda não têm o reconhecimento da sociedade, que avalia a enfermagem como uma profissão subordinada e complementar. Ainda, o mesmo autor afirma que a profissão só será reconhecida pela sociedade quando as equipes estiverem estruturadas, organizadas
Participação Sociopolítica dos Profissionais

internamente como classe. Além disso, descreve que o enfermeiro é uma classe invisível, que os pacientes o confundem com médico e que os técnicos são os enfermeiros, emergindo daí a necessidade do trabalho do marketing profissional.

A invisibilidade do enfermeiro na política também é relatada por Lessa ${ }^{11}$, pois o profissional perde sua identidade de enfermeiro para ganhar o título do cargo que ocupa, passando a ser gerente, coordenador, presidente, e não mais enfermeiro, com um rol de funções administrativas que o afasta dos fundamentos assistenciais.

Nas áreas de formação em saúde, o processo educacional contínuo tem sido uma constante. $\mathrm{Na}$ enfermagem, existe essa preocupação para garantir assistência de qualidade à sociedade. Dessa forma, compreende-se que um dos componentes básicos para a promoção da saúde seja a qualificação do profissional ${ }^{16}$. Os profissionais de nível superior possuem maior conhecimento $(\mathrm{p}<0,001)$ do Código de Ética, o que reforça tal afirmação, pois o código de ética dos profissionais de enfermagem inclui a Educação Continuada no capítulo II - Dos Direitos, e III - Das Responsabilidades ${ }^{17}$. Assim, entende-se que é direito e dever do profissional atualizar-se e manter-se atualizado em benefício do sujeito-do-cuidado, da coletividade e do desenvolvimento da profissão. 
Revista Eletrônica Gestão \& Saúde ISSN: 1982-4785

Pereira MP, Castro CFD, Fiorin BH

No cenário de interesse político e de envolvimento em movimentos, nota-se que os profissionais de nível superior possuem também maior interesse por essas questões $(\mathrm{p}<0,005$ e $\mathrm{p}<0,045, \quad$ respectivamente) Segundo Santos ${ }^{18}$, a enfermagem demorou a participar e se organizar como categoria de trabalhadores, vivendo uma situação de consolidação de divisão de trabalho. À medida que se organizava, a classe definia sua identidade social. A convivência com outros trabalhadores, segundo Santos ${ }^{18}$ e Gomes ${ }^{19}$, foi decisiva para que essa classe se inserisse nos movimentos e lutas, não só trabalhistas como em todos que atingissem a sociedade. É preciso que todos os profissionais de enfermagem se mobilizem para conquistar novos espaços e reinventar a prática cotidiana do saber e do fazer nas atividades da categoria.

\section{Conclusão}

Em relação ao quantitativo de profissionais da pesquisa, a equipe de enfermagem composta por profissionais de nível técnico foi numericamente maior do que a composta por enfermeiros, o que já era esperado pela distribuição usual dos profissionais. Em relação às lutas de classe, percebe-se maior interesse dos enfermeiros, com participações da classe masculina em maior número, embora fossem a minoria na equipe.

\section{Participação Sociopolítica dos Profissionais}

Ainda existem profissionais que não conhecem nem participam de qualquer entidade de representação, mesmo sabendo que a associação ao COREN é obrigatória para o exercício da enfermagem.

Construir um artigo que relacione a vivência política com o perfil do profissional de enfermagem constituiu-se um desafio, em especial pela pouca produção abordando especificamente essa temática tão importante e, ao mesmo tempo, tão necessária à consolidação, formação e subsídio de processos seletivos, atividades de treinamento, aperfeiçoamento e desenvolvimento contínuo. Percebe-se que a organização política da enfermagem brasileira é permeada de avanços e retrocessos. Embora exista um número expressivo de interesse na política, ainda estamos à procura dos meios de ação na atuação conjunta.

Espera-se, com esta pesquisa, contribuir para otimização de recursos e investimentos na enfermagem e na promoção da retenção de capital intelectual, fazendo emergir, assim, a necessidade de produzir conhecimentos referentes à equipe de enfermagem.

Não se pretende com este artigo esgotar o debate referente ao tema, mas contribuir para reflexões e produção de estudos que versem sobre a aproximação da ética e da política com a formação do enfermeiro. É necessário, a cada dia, lutar ainda mais para que os ideais da profissão sejam mantidos e que o 
Revista Eletrônica Gestão \& Saúde ISSN: 1982-4785 Pereira MP, Castro CFD, Fiorin BH

envolvimento nos processos decisórios, bem como a associação nas entidades representativas, sejam ampliados. Somente com a mobilização de todos os profissionais será possível avançar nesse sentido.

\section{Referências}

1. Pires DEP. Transformações necessárias para o avanço da Enfermagem como ciência do cuidar. Rev Bras Enferm. 2013; 66(esp): 39-44.

2. Mininel VA, Baptista PCP, Felli VEA. Cargas psíquicas e Processos de desgaste em Trabalhadores de enfermagem de hospitais Universitários Brasileiros. Rev. Latino-Am. Enfermagem. 2011; 19(2): 340-7.

3. Cezar ES, Marziale MHP. Occupational violence problems in an emergency hospital in Londrina, Parana, Brazil. Cad ${ }^{[15]}$ Saúde Publica, Rio de Janeiro, 2006; 22(1):217-221.

4. Costa RA, Shimizu HE. Atividades desenvolvidas pelos enfermeiros nas unidades de internação de um hospital-escola. Rev Latino-Am Enferm 2005;13(5): 654-62.

5. Machado, HM, Vieira ALS, Oliveira E. Construindo o perfil da enfermagem. Rev. Enfermagem em Foco. 2016; 7(ESP): 35-62.

6. IBGE - Instituto Brasileiro de Geografia e Estatística (IBGE). Censo demográfico. Rio de janeiro, 2010.

7. Machado MH, Aguiar Filho W, Lacerda WF, Oliveira E, Lemos W, Wermelinger M, Et al. Características Gerais da Enfermagem: O Perfil sociodemográfico. Rev Latino-Am Enferm (Internet). 2016 (Acesso em 22 Fev. 2016); Disponível em: http://revista.portalcofen.gov.br/index.php/ enfermagem/article/view/686.
Participação Sociopolítica dos Profissionais

8. Persegona KR, Rocha DLB, Lenardt MH, Zagonel IPS. O Conhecimento político na atuação do enfermeiro. Esc Anna Nery Rev Enferm (Internet). 2009 (Acesso em 15 Mai. 2009); 13 (3): 645-50. Disponível em: http://www.scielo.br/pdf/ean/ v13n3/v13n3a27.pdf.

9. Melo CMM, Santos TA. A participação política de enfermeiras na gestão do Sistema Único de Saúde em nível municipal. Texto contexto - enferm. (Internet). 2007 [Acesso em 23 Ago. 2016); 16 (3): 426-432. Disponível em: http://www.scielo.br/scielo.php? script=sci_arttext\&pid=S010407072007000300007\&lng=en.

10. Oliveira AAS, Leite LP. Construção de um sistema educacional inclusivo: um desafio políticopedagógico. Ensaio: Aval. Pol. Públ. Educ. 2007; 15(57): 511-524.

11. Lessa ABSL, Araújo CNV. Brazilian nursing: a reflection about political activity. Reme: Revista Mineira de Enfermagem. 2013; 17 (2): 481-7.

12. Santos RM, Trezza MCSF, Barros WO, Leite JL. História e perspectivas da organização dos enfermeiros nos movimentos sindicais. Rev. bras. enferm. 2006; 59 (1): 89-94.

13. Brasil. Constituição. Lei $n^{\circ} 7498$, de 25 de Junho de 1986. Dispõe sobre a regulamentação do exercício da enfermagem, e dá outras providências. Brasília: 1986.

14. Fortes PAC. Ética e saúde: questões éticas, deontológicas e legais, tomada de decisões, autonomia e direitos do paciente, estudo de casos. São Paulo: EPU, 1998.

15. Schneider DG, Ramos FRS. Nursing ethical processes in the State of Santa Catarina: characterization of factual elements. Revista Latino-americana de Enfermagem. 2012; 20 (4): 744-752.

16. COFEN (MG). Resolução COFEN n.240/2000. Aprova o Código de Ética dos Profissionais de 
Revista Eletrônica Gestão \& Saúde ISSN: 1982-4785

Pereira MP, Castro CFD, Fiorin BH

Enfermagem e da outras Providências. Boletim do COREN, Belo Horizonte (MG) 2003 set; 9(1):3948.

17. Ferraz F. O Processo de Vinculação da Educação Continuada em Serviço, com a Equipe de Enfermagem no Cuidado Terapêutico ao Cliente Hemato-oncológico Adulto. (Monografia de Graduação). Santa Maria (RS): Universidade Federal de Santa Maria; 2003.

18. Santos RM, Trezza MCSF, Barros WO, Anunciação WM. A organização sindical da 9 saúde e a enfermagem: uma (re) análise oportuna. In: Anais do $60^{\circ}$ Congresso Brasileiro de Enfermagem, Rio de Janeiro: 2003.

19. Gomes MLB, Baptista SS, Silva ICM. A luta pela politização das enfermeiras: sindicalismo no Rio de Janeiro - 1978/1984. Rio de Janeiro (RJ): Ed. EEAN/UFRJ, 1999.
Participação Sociopolítica dos Profissionais

\section{Participação dos autores:}

PEREIRA, MP trabalhou na concepção teórica, coleta de dados, análise estatística e elabolaração e redação final do texto.

CASTRO, CFD trabalhou na concepção teórica, elaboração, análise estatística e redação final do texto.

FIORIN, BH trabalhou na concepção teórica, elaboração, análise estatística e redação final do texto, submissão do artigo ao periódico, revisão pós parecer dos revisores.

Recebido: 13.02.2019

Revisado: 13.02.2019

Aprovado: 06.05.2019 